UK Survey of discharge prescriptions, transcribing and development of the hospital pharmacist-prescribing role

Sewell, GJ

http://hdl.handle.net/10026.1/3736

International Journal of Pharmacy Practice

All content in PEARL is protected by copyright law. Author manuscripts are made available in accordance with publisher policies. Please cite only the published version using the details provided on the item record or document. In the absence of an open licence (e.g. Creative Commons), permissions for further reuse of content should be sought from the publisher or author. 


\section{UK survey of discharge prescriptions, transcribing and development of the hospital pharmacist-prescribing role}

\section{R. J. HOBSON and G. J. SEWELL}

Introduction The Audit Commission's report "A spoonful of sugar" has identified the pharmacist as a central figure in medicines management. This report echoes recommendations in the Crown report, ${ }^{2}$ which advocated the extension of prescribing rights to pharmacists.

Within secondary care, some pharmacists are already prescribing dependently, the most common role being transcribing of discharge prescriptions. ${ }^{3,4}$

Reported advantages of pharmacist discharge prescription transcription services (PDPTS) include an increased number of pharmacist interventions, increased prospective interventions, decreased prescription turnover time, cost savings by using patients' own drugs (PODs), decreased out-of-hours work for the pharmacy department, decreased prescription error rate compared with doctors and releasing doctor and nurse time. 3,4

A recent study established that one third of 162 hospital trusts surveyed involved pharmacists in writing discharge prescriptions, but their overall impact on the total number of prescriptions being written was negligible. ${ }^{5} \mathrm{~A}$ questionnaire was therefore developed to further explore these findings, and to identify other pharmacist prescribing roles.

Method The questionnaire was developed after literature review and visits to hospitals running PDPTS. It contained open and closed questions. Face-to-face interviews with pharmacists were used for validation. Single hospitals in each UK NHS trust were identified using the UK drug information pharmacists' group directory and the Chemist \& Druggist directory. Ambulance trusts, learning disabilities trusts and community hospitals were excluded.

The questionnaire was piloted in 20 randomly selected hospitals (July 2001) and then distributed (August 2001). It was addressed to the chief pharmacist, principal pharmacist or clinical services manager according to the name found.

Responses were coded and analysed using the statistical package for the social sciences (SPSS) version 10.

\section{FOCAL POINTS}

$\square$ A questionnaire survey was distributed to one acute hospital from each UK NHS trust to examine pharmacist discharge prescription transcription services (PDPTS)

$\square$ Thirty-six per cent of hospital pharmacy departments (HPD) who responded were offering PDPTS. Prescribing activities included pharmacist prescription amendment (29 per cent), prescribing activity in pre-admission clinics (18 per cent) and re-writing drug charts (16 per cent); $\mathbf{4 4}$ per cent did not undertake any prescribing activity $\square$ Typically, the service operated from 9am to $5 \mathrm{pm}$, Monday to Friday (68.1 per cent), and most frequently serviced the medical directorate (51.1 per cent), followed by the surgical directorate ( 36.2 per cent); the service was normally funded by the pharmacy department ( 58.3 per cent), and mainly operated by $\mathrm{C}$ and $\mathrm{D}$ grade pharmacists $\square$ Typically one or two pharmacists ran the service for their own wards and each produced fewer than five prescriptions per day

Results The questionnaire was sent to 206 NHS trusts, and the response rate was 66 per cent (135/206); (36 per cent (49/135) of hospital pharmacy departments (HPD) who responded were offering PDPTS.

Prescribing activities included pharmacist prescription amendment ( $n=39,29$ per cent), prescribing ac tivity in pre-admission clinics $(n=24$, 18 per cent) and rewriting drug charts ( $n=20,16$ per cent). Fifty-nine HPDs (44 per cent) did not undertake any prescribing activity.

Among those HPDs that do not transcribe, 68.6 per cent $(n=59 / 86)$ undertake no prescribing activities (range 0 to 3). Among those that do transcribe, there was a wider range in the number of prescribing activities undertaken (range 1 to 8 ), median $=3, n=13 / 49$ (26.5 per cent).

There was a tentative relationship between the total number of pharmacists employed at a hospital and the total number of pharmacist prescribing activities (correlation coefficient $=0.208, P=0.018$ ).

Typically, the service operated from 9 am to $5 \mathrm{pm}$, Monday to Friday $(n=32,68.1$ per cent), and most frequently serviced the medical directorate ( $\mathrm{n}=24,51.1$ per cent), followed by the surgical directorate $(n=17,36.2$ per cent).

The service was normally funded by the pharmacy department $(n=28$,
58.3 per cent), and mainly operated by $C$ and $D$ grade pharmacists.

The most frequently used model of service was pharmacists writing the discharge prescriptions for their own wards ( $n=38,77.6$ per cent).

Typically one $(n=7)$ or two $(n=8)$ pharmacists ran the service, and each pharmacist produced less than 5 prescriptions per day ( $n=25,52.1$ per cent).

Discussion The results of this survey show that most HPDs who run a PDPTS do not have a large impact on the overall number of discharge prescriptions written in the hospital. This agrees with Sexton's results. ${ }^{5}$

The results suggest that manpower is a key obstacle in the provision of PDPTS and other pharmacist prescribing roles. HPDs could seek financial support for extension of prescribing services from other directorates and also funding for nurses and doctors.

A limitation of this study is it would have been preferable to send the questionnaire to every UK hospital as opposed to one per trust.

Future research should determine the attitudes of other health care professionals and patients to pharmacists becoming supplementary and independent prescribers, as support within a multidisciplinary team is key in effective implementation.
Department of Pharmacy and Pharmacology, University of Bath, and Swindon and Marlborough NHS Trust

R. J. Hobson

Department of Pharmacy and Pharmacology, University of Bath, and Plymouth Hospitals NHS Trust G. J. Sewell

Int J Pharm Pract 2002:10(suppl):R12

\section{References}

1. Audit Commission. A spoonful of sugar: medicines management in NHS hospitals. London: Audit Commission; 2001. 2. Department of Health. Review of prescribing, supply and administration of medicines: final report. London: Department of Health; 1999.

3. Boorman S, Cairns C. Another way forward for pharmaceutical care a team-based clinical pharmacy service. Pharm J 2000;264: 343-6.

4. Cattell R, Conroy C, Sheikh A. Pharmacist integration into the discharge process: a qualitative and quantitative impact assessment. Int J Pharm Pract 2001;9:59-64. 5. Sexton J, Ho YJ, Green CF, Caldwell NA. Ensuring seamless care at hospital discharge: a national survey. J Clin Pharm Therap 2000;25: 385-393. 